\title{
Desarrollo de un hospital virtual en el curso de especialistas en anestesiología en Argentina
}

\author{
Development of a virtual hospital in the training of residents of anesthesiology in \\ Argentina
}

\author{
Carlos D. Romero ${ }^{1,2 *}$, Miguel Á. Barboza-Piedras ${ }^{3}$ y Ma. Florencia Pol4
}

${ }^{1}$ Subdirección, Curso de Especialistas de Anestesiología (AAARBA); ${ }^{2}$ Departamento de Anestesiología, Hospital Británico; ${ }^{3}$ Dirección, Curso de Especialistas de Anestesiología (AAARBA); ${ }^{4}$ Coordinación Académica, Curso de Especialistas en Anestesiología (AAARBA). Buenos Aires, Argentina

A lo largo de los años, la educación médica tradicional se ha enfocado en el desarrollo del conocimiento, las destrezas y las aptitudes; en cambio, el mundo moderno se ha dirigido a una educación que atiende la competitividad y la capacidad de adaptarse a los cambios sociales y tecnológicos. En este escenario, los médicos en formación se desarrollan como futuros especialistas y son evidentes los efectos que las circunstancias inesperadas pueden tener en el proceso de aprendizaje.

En el sistema de formación de los médicos residentes, definido como un régimen de capacitación en servicio, el hospital es por excelencia el área de adquisición de competencias. El número de residentes asignados a cada unidad asistencial depende del volumen operativo de cada una.

La pandemia generada por el virus SARS-Cov2 ha tenido un efecto negativo sobre todos los niveles de formación de los médicos residentes, con algunas diferencias según sea el hospital examinado. En un extremo se encuentra un reducido número de hospitales en los que, a pesar de verse atenuada su actividad, hay todavía un volumen mínimo necesario para que la docencia pueda llevarse a cabo. En el otro extremo se hallan los que han disminuido su actividad quirúrgica, a tal punto que solo funciona el servicio de guardia con una mínima actividad quirúrgica programada.

Esta reducción del número de quirófanos y procedimientos practicados en cada uno de ellos ha provocado un deterioro de las condiciones para una actividad docente sistemática. Esto no solo afecta a los alumnos que ingresaron al programa de residencia durante la pandemia (2020 y 2021), sino también a los residentes superiores.

La ocupación de camas en la unidad de terapia intensiva (UTI), imposibilita recibir a los pacientes que, por la complejidad de la operación o el grado de comorbilidad, necesitan ese ámbito para la vigilancia en el posoperatorio. Como consecuencia, se han pospuesto todas las intervenciones que no sean inaplazables, lo que limita el número de procedimientos en los que participan los alumnos. Al día de hoy se ha observado una disminución crítica de la oferta docente frente a una ávida demanda de los residentes, con la dramática situación de que el tiempo de residencia (tiempo de formación) transcurre inexorablemente y las oportunidades de realizarla son mínimas e inapropiadas.

Ante tal panorama se desarrolló el hospital virtual de la carrera de especialistas en anestesiología como elemento educativo acoplado al entorno virtual de aprendizaje y a la simulación de alta fidelidad.
Correspondencia:

${ }^{*}$ Carlos D. Romero

E-mail: carlos.romero@anestesia.org.ar DOI: 10.24875/RAA.M21000001 un artículo open access bajo la licencia CC BY-NC-ND (http://creativecommons.org/licenses/by-nc-nd/4.0/). 


\section{¿Qué hacer para subsanar en parte el déficit de la formación profesional?}

Se considera que si bien las consecuencias de esta prolongada situación serán difíciles de revertir en su totalidad, la implementación de acciones creativas y focalizadas, que tengan en cuenta los aspectos particulares que se presenten en cada lugar, será de ayuda al momento de redirigir la curva actual.

La creación de un hospital virtual en el ámbito de un centro de simulación de alto nivel representa un aporte factible y significativo, es decir, la creación de un espacio que haga posible la adquisición de competencias, imprescindible en estos momentos de disminución de las posibilidades de aprendizaje.

\section{El hospital virtual acoplado a los simuladores de alta fidelidad}

La simulación es la representación artificial simplificada de un proceso complejo que sucede en el mundo real con la fidelidad suficiente para lograr un objetivo y, de esa manera, poder evaluar desde el desempeño en un determinado procedimiento hasta la formación integral de manera sistemática. Es necesario comprender que no se trata tan solo de simuladores complejos y costosos, sino de una herramienta educativa en la cual confluyen distintos procesos de aprendizaje.

Los avances en simulación habitualmente se relacionan con la industria aérea, con sus primeros pasos plasmados en el histórico Simulador Antoinette (que aún se puede ver en la galería del Airbus Training Centre de Toulouse, Francia), pero la realidad es que las prácticas de simulación se remontan a tiempos lejanos, cuando se utilizaban muñecos montados a caballo para el entrenamiento de los guerreros ${ }^{1}$. A pesar de ello, fue la industria aérea la que aportó y motorizó el desarrollo de la simulación durante la Primera Guerra Mundial, al idear modelos estáticos para que los pilotos "conocieran" los aviones y más tarde (Segunda Guerra Mundial) al introducir los elementos dinámicos.

En el área de la anestesiología, el primer simulador lo desarrollaron en 1966 Abrahamson y Denson (Universidad de California) para capacitar a los residentes de anestesiología en el procedimiento de la intubación endotraqueal. Estos investigadores demostraron que los residentes entrenados a lo largo de dos semanas en el simulador Sim One lograban un grado de desempeño adecuado en el quirófano en menor tiempo en comparación con los residentes sin entrenamiento en simuladores ${ }^{2}$.

En la actualidad existe una amplia gama de simuladores que aportan una notable fidelidad; tal ha sido el avance de la simulación en el área académica y científica que en el año 2006 se editó la revista oficial Simulation in Healthcare ${ }^{3}$.

\section{El hospital virtual}

El desarrollo del hospital virtual, concebido como una parte del entorno virtual de aprendizaje, requiere una estrecha interacción con los simuladores de alta fidelidad y el equipo humano afectado a su funcionamiento (profesores, instructores, ingenieros, actores).

El punto de partida del hospital virtual es la selección de una serie de pacientes "virtuales" por parte de un docente a cargo, quien desarrolla el marco introductorio de los casos clínicos a través de los recursos informáticos que proporciona el campus virtual de la institución. De ese modo, luego de identificar los antecedentes patológicos, la condición clínica y la analítica (estudios de laboratorio, etc.), se emite una alerta al grupo de alumnos asignados y se desarrolla la lista quirúrgica semanal, como también su distribución en el centro de simulación de la institución, que cuenta con simuladores SimMan 3G montados sobre escenarios de salas quirúrgicas (mesas de anestesia, desfibriladores, carros de vía aérea, etc.).

Cada operación simulada cuenta con dos "actores cirujanos" y un "actor asistente" del residente, quien facilita sus requerimientos (el residente ejecuta, desde la canalización venosa o el bloqueo regional ecoguiado hasta la extubación, la elaboración del parte anestésico y el plan de analgesia posoperatoria), mientras en una sala contigua se observa y se registran las acciones y el desarrollo de la simulación, para suministrar al final la información de retorno (debriefing).

Durante la simulación del acto quirúrgico se ejecutan diferentes situaciones que pueden presentarse durante una operación regular (intubación difícil, ventilación difícil, hipotensión arterial, hemorragia masiva, arritmas intraoperatorias, etc.) y se registran en el portafolio personal de cada residente su desempeño y su evolución. Algunas de las actividades (p. ej., manejo de la vía aérea) se registran a través de un sistema de actividades profesionales confiables (APROC). Una APROC es una actividad estructurada que, una vez cumplida de manera adecuada, da cuenta del correcto aprendizaje efectuado por el residente, y permite certificar la medida 
de adquisición de competencias de un modo cuantitativo o, expresado de otra manera, es una tarea clave de una disciplina (profesión, especialidad o subespecialidad) que puede confiarse en que una persona la realizará sin supervisión directa en un contexto de atención de salud particular, una vez que haya demostrado suficiente competencia ${ }^{4}$.

Si bien no se han detallado en las publicaciones médicas la utilidad y la efectividad de la estrategia de un hospital virtual acoplado a un centro de simulación, es una alternativa novedosa y complementaria para la formación de médicos residentes en anestesiología para la adquisición de competencias.

\section{Bibliografía}

1. Millán J, Palés J, Morán J. Principios de educación médica. Ed. Panamericana 2015:263-271.

2. Abrahamson S, Denson JS, Wolf RM. Effectiveness of a simulator in training anesthesiology residents. J Med Educ. 1969;44(6):515-9.

3. Cooper J, Taqueti V. A brief history of the development of mannequin simulators for clinical education and training. Qual Saf Health Care. 2004;13(Suppl 1): i11-i18.

4. Hamui A, Durán V, García S, Varela T, Millán M, Gutiérrez S. Avances del modelo educativo para desarrollar actividades profesionales confiables. Educ Med. 2018;19(5):294-300. 